Tropical Journal of Pharmaceutical Research April 2018; 17 (4): 619-626

ISSN: $1596-5996$ (print); 1596-9827 (electronic)

(C) Pharmacotherapy Group, Faculty of Pharmacy, University of Benin, Benin City, 300001 Nigeria.

\title{
Optimization of extraction of polyphenols from Sorghum Moench using response surface methodology, and determination of their antioxidant activities
}

\author{
Liu Liu ${ }^{1}$, Long Chen ${ }^{1}$, Arshad Mehmood Abbasi ${ }^{2}$, Zichao Wang ${ }^{3}$, Dianxin $\mathrm{Li}^{4 \star}$, \\ Yingbin Shen ${ }^{1 *}$ \\ ${ }^{1}$ Department of Food Science and Engineering, School of Science and Engineering, Jinan University, Guangzhou 510632, \\ Guangdong, China, ${ }^{2}$ Department of Environmental Sciences, COMSATS Institute of information Technology, Abbottabad, \\ Pakistan, ${ }^{3}$ College of Biological Engineering, Henan University of Technology, Zhengzhou 45000, Henan, ${ }^{4}$ Guangdong \\ Vocational College of Science and Trade, Department of Biotechnology, Guangdong Province, Guangzhou 510000, China
}

*For correspondence: Email: shenybin412@gmail.com, Idx2008403@126.com; Tel: +86-13580316270, +86-13660320534

\begin{abstract}
Purpose: To employ response surface methodology (RSM) hinged on a central composite design (CCD) for the optimization of the extraction of polyphenols from Sorghum moench (Sorghum M). Methods: The combined influence of independent variables were assessed with RSM. Total phenolic content (TPC) determination was carried out using Folin-Ciocalteu method. Derivative compounds of phenolic acid were assayed using high performance liquid (HPLC). Antioxidant potential was determined through 1,1-diphenyl-2- picrylhydrazyl (DPPH) radical scavenging test.

Results: The optimized extraction conditions were: $60.37 \%$ ethanol, temperature of $59.07^{\circ} \mathrm{C}$ and 2.97 $h$ of extraction duration, which resulted in the extraction of maximum amount of TPC, i.e., $313 \mathrm{mg}$ GAE/100g dry weight. The interactions between temperature and ethanol concentration, and between extraction time and ethanol concentration had significant effects of TPC $(p<0.05)$. Under these conditions, there was a consistency between the projected and actual experimental levels of polyphenols. A positive correlation was found between TPC and DPPH radical scavenging activity $(r=0.67, p<0.05)$. Furthermore, ferulic acid correlated positively with $p$-coumaric acid $(r=0.54, p<0.01)$. Conclusion: These results underscore the usefulness of conditions for extraction in accurate quantification of antioxidants and phenolic compounds from Sorghum $M$, for possible application in large scale commercial extraction.
\end{abstract}

Keywords: Response surface methodology, Sorghum moench, Polyphenols, Antioxidants

\begin{abstract}
This is an Open Access article that uses a funding model which does not charge readers or their institutions for access and distributed under the terms of the Creative Commons Attribution License (http://creativecommons.org/licenses/by/4.0) and the Budapest Open Access Initiative (http://www.budapestopenaccessinitiative.org/read), which permit unrestricted use, distribution, and reproduction in any medium, provided the original work is properly credited.

Tropical Journal of Pharmaceutical Research is indexed by Science Citation Index (SciSearch), Scopus, International Pharmaceutical Abstract, Chemical Abstracts, Embase, Index Copernicus, EBSCO, African Index Medicus, JournalSeek, Journal Citation Reports/Science Edition, Directory of Open Access Journals (DOAJ), African Journal Online, Bioline International, Open-J-Gate and Pharmacy Abstracts
\end{abstract}

\section{INTRODUCTION}

Sorghum moench ranks next to wheat as one of the very important cereal grains worldwide [1]. Sorghum is cultivated arid, tropical, and sub- tropical regions, and is very cost-effective to produce because of its ability to adapt to different stress in the environmental. Humans consume over $35 \%$ of sorghum produced globally, while the remaining $65 \%$ is used for industrial 
production of alcohol and for making feed for lower animals [2]. Studies have revealed that sorghum is a good source of some beneficial antioxidant phytochemical compounds such as anthocyanins, polyphenols, sterols and tannins [3]. Thus sorghum can offer protection against free radical-induced oxidative damage. Sorghum is receiving a lot of interest in the US due to its desirable food qualities such as negligible gluten content, minimal digestibility, anti-carcinogenic potential and low cholesterol index [2].

The type, yield and stability of extracts are affected by factors such as duration of extraction, solvent used, and extraction temperature. Variations in these factors affect the levels and antioxidant potential of TPCs [4]. Thus, it is important to optimize extraction conditions to maximize extract yield.

Response surface methodology (RSM) is a useful approach for assessing the interactions between stipulated response variables and various factors that influence them [5]. In addition, RSM is an excellent statistical approach for optimizing variables, and if properly used, it identifies optimal conditions for process improvement. It is useful for defining the influence of single or combined independent variables on the process, being that interactions cannot be determined by considering the various factors one-at-a-time. .The most frequently used form of RSM is central composite design (CCD) [6]. Therefore, research methodology with CCDis employed in the elucidation of interactions between factors because it is an accurate procedure for process design and product.

A previous study reported the antioxidant activity of Sorghum M species [7]. However, not much is known about the optimization of the extraction of TPC of Sorghum $M$ with RSM method. The objectives of this study were to (a) optimize the extraction of TPC, ferulic acid, catechin and $p$ coumaric acid from Sorghum M from CCD; (b) evaluate the extracts for their DPPH radical scavenging potential, and (c) determine Pearson's correlation coefficients between antioxidant potential and TPC.

\section{EXPERIMENTAL}

\section{Chemicals and materials}

The free radical DPPH was product of SigmaAldrich (St. Louis, USA). Other reagents were analytical in quality. The Sorghum M (Liaotian 1) sample was purchased from a market vendor in Wuxi, China. The sorghum grains were ground to powder, sieved through a 60-mesh screen and preserved at $-20{ }^{\circ} \mathrm{C}$ prior to use.

\section{Sample preparation}

The sorghum flour was subjected to extraction with ethanol: water at different volume ratios (Table 1). Flour $(1 \mathrm{~g})$ was added to $10 \mathrm{~mL}$ of appropriate ethanol: water ratio and subjected to extraction at different temperatures in line with the design in Table 1. The extraction process was twice on the residue. In each case, the homogenate was clarified by centrifugation for 20 min at $3000 \mathrm{~g}$, and the clear extracts were kept at $4{ }^{\circ} \mathrm{C}$ prior to analyses.

Table 1: Matrix of the model and combination of variables

\begin{tabular}{|c|c|c|c|c|c|c|}
\hline \multirow{2}{*}{$\begin{array}{l}\text { Trea } \\
\text { tme } \\
\text { nt } \\
\text { cod } \\
\text { e }\end{array}$} & \multicolumn{3}{|c|}{ Level code } & \multicolumn{3}{|c|}{$\begin{array}{c}\text { Levels of the } \\
\text { variables }\end{array}$} \\
\hline & $\begin{array}{c}\text { Sol } \\
\text { ven } \\
t^{b}\end{array}$ & $\begin{array}{c}\text { Temper } \\
\text { ature } \\
\left({ }^{\circ} \mathrm{C}\right)\end{array}$ & $\begin{array}{c}\text { Tim } \\
e \\
\text { (h) }\end{array}$ & $\begin{array}{c}\text { Sol } \\
\text { ven } \\
t^{b}\end{array}$ & $\begin{array}{c}\text { Temper } \\
\text { ature } \\
\left({ }^{\circ} \mathrm{C}\right)\end{array}$ & $\begin{array}{c}\text { Tim } \\
\boldsymbol{e} \\
(\boldsymbol{h}) \\
\end{array}$ \\
\hline 1 & 0 & -1.68 & 0 & 60 & 26.36 & 2.5 \\
\hline 2 & -1 & -1 & -1 & 80 & 40 & 4 \\
\hline 3 & 1 & -1 & -1 & 40 & 40 & 1 \\
\hline 4 & -1 & -1 & 1 & 80 & 40 & 1 \\
\hline 5 & 1 & -1 & 1 & 40 & 40 & 4 \\
\hline 6 & $\begin{array}{c}- \\
1.6 \\
8\end{array}$ & 0 & 0 & 60 & 60 & $\begin{array}{c}5.0 \\
2\end{array}$ \\
\hline 7 & $\begin{array}{c}1.6 \\
8\end{array}$ & 0 & 0 & 60 & 60 & 0 \\
\hline 8 & 0 & 0 & $\begin{array}{c}- \\
1.6 \\
8\end{array}$ & 60 & 60 & 2.5 \\
\hline 9 & 0 & 0 & $\begin{array}{c}1.6 \\
8\end{array}$ & $\begin{array}{l}26 . \\
36\end{array}$ & 60 & 2.5 \\
\hline 10 & 0 & 0 & 0 & 60 & 60 & 2.5 \\
\hline 11 & 0 & 0 & 0 & 60 & 60 & 2.5 \\
\hline 12 & 0 & 0 & 0 & 60 & 60 & 2.5 \\
\hline 13 & 0 & 0 & 0 & 60 & 60 & 2.5 \\
\hline 14 & 0 & 0 & 0 & $\begin{array}{l}93 . \\
64\end{array}$ & 60 & 2.5 \\
\hline 15 & 0 & 0 & 0 & 60 & 60 & 2.5 \\
\hline 16 & -1 & 1 & -1 & 40 & 80 & 1 \\
\hline 17 & 1 & 1 & -1 & 80 & 80 & 4 \\
\hline 18 & -1 & 1 & 1 & 40 & 80 & 4 \\
\hline 19 & 1 & 1 & 1 & 80 & 80 & 1 \\
\hline 20 & 0 & 1.68 & 0 & 60 & 93.64 & 2.5 \\
\hline
\end{tabular}

\section{Experimental design}

The simulataneous influence of two process variables on TPC content of sorghum extracts was determined with an orthogonal rotatable $\mathrm{CCD}$ for $\mathrm{K}=3$ factors in a quadratic function, with ethanol concentration and temperature as variables, while TPC and DPPH radical scavenging ability formed the responses (Table 1). 


\section{Assay of TPC}

The levels of TPC were estimated in a colorimetric reaction with Folin-Ciocalteu reagent [8]. The reaction mixture contained equal aliquots of TCP extract and saturated $\mathrm{NaCO}_{3}$, and $1 \mathrm{~mL}$ of Folin-Ciocalteau reagent. After mixing and incubating for $30 \mathrm{~min}$ at room temperature, the absorbance of the solution was read at $765 \mathrm{~nm}$. The TPC contents were calculated as equivalents of gallic acid (GAE) per gram of extract dry weight (DW).

\section{Determination of phenolic acids}

The phenolic acids contents of the various extracts were determined using HPLC according to the procedure of Guo et al [9], with some modifications. The HPLC system employed a separation mode using a Waters 1525 binary pump and Waters photodiode detector (Milford, MA,USA). Manual injection volume was $20 \mu \mathrm{L}$, and the sample components were separated at $35{ }^{\circ} \mathrm{C}$ in a $250 \times 4.6,5 \mu \mathrm{m}$ Agilent $\mathrm{C}_{18}$ column with gradient elution using methanol (solvent $\mathrm{A}$ ) and $0.1 \%$ acetic acid-water solution (solvent $B$ ) (flow rate $=0.8 \mathrm{~mL} / \mathrm{min}$ ). For characterization of the peaks, the UV spectra were obtained in the range of $254-400 \mathrm{~nm}$. Peak area at maximum absorption was employed in calculating the phenolic acid levels.

\section{Assay of DPPH radical scavenging activity}

This was carried out according to a method described previouly [10]. The DPPH radical scavenging activity (D) was calculated as in Eq 1.

$D(\%)=\{(A c-A s) / A c\} 100$

\section{Statistical analysis}

The data are expressed as mean $\pm S D$, and were analyzed by Students' t-test using Design Expert 7.0. Statistical significance was assumed at $p<$ 0.05 .

\section{RESULTS}

Table 2 shows DPPH radical scavenging activity and TPC levels of the extracts. The TPC and $\mathrm{DPPH}$ radical scavenging potential were influenced not only by the type of solvent used, but also by the conditions used for extraction.

The four models shown in Table 2 were obtained by using DDPH radical scavenging ability, TPCs, catechin, ferulic acid, and $p$-coumaric acid as response variables in RSM, while the fitted TPC model parameters are presented in Table 3 . Statistical significance $(p<0.05)$ was seen in $A, B$ and $C$ (lines variables), and in $A^{2}, B^{2}$ and $C^{2}$ (quadratic variables), which indicated polyphenol extractability was strongly influenced by these factors. Two of the two-variable interactions $A B$ and $A C$ had significant influences $(p<0.05)$ affected extraction yield, but BC interaction did not produce any significant influence $(p>0.05)$. These are reflected in the regression equation:

Table 2: Response of the model to extracts

\begin{tabular}{llllll}
\hline Code & TPC & \multicolumn{1}{c}{ DPPH } & \multicolumn{1}{c}{ FA } & \multicolumn{1}{c}{ PC } & C \\
\hline 1 & $201.01 \pm 2.18$ & $74.4 \pm 0.34$ & $5.34 \pm 0.22$ & $15.29 \pm 0.51$ & $9.27 \pm 0.78$ \\
2 & $277.24 \pm 3.02$ & $85.5 \pm 0.36$ & $7.29 \pm 0.32$ & $21.70 \pm 2.11$ & $12.33 \pm 1.12$ \\
3 & $227.52 \pm 2.01$ & $77.2 \pm 0.79$ & $6.12 \pm 0.43$ & $19.15 \pm 1.06$ & $13.65 \pm 1.21$ \\
4 & $226.79 \pm 1.98$ & $85.9 \pm 0.76$ & $13.87 \pm 1.21$ & $32.32 \pm 2.78$ & $17.51 \pm 1.07$ \\
5 & $262.82 \pm 2.03$ & $77.9 \pm 0.16$ & $22.65 \pm 2.12$ & $34.69 \pm 2.89$ & $7.42 \pm 0.32$ \\
6 & $282.64 \pm 2.11$ & $89.3 \pm 0.08$ & $33.84 \pm 3.09$ & $7.91 \pm 0.88$ & $11.68 \pm 1.09$ \\
7 & $212.96 \pm 2.08$ & $92.4 \pm 0.10$ & $16.55 \pm 1.12$ & $38.64 \pm 2.06$ & $8.20 \pm 0.29$ \\
8 & $308.44 \pm 2.49$ & $77.0 \pm 0.85$ & $7.32 \pm 0.72$ & $3.46 \pm 0.21$ & $13.58 \pm 1.32$ \\
9 & $287.99 \pm 2.76$ & $92.08 \pm 2.3$ & $20.47 \pm 1.08$ & $31.37 \pm 1.21$ & $7.27 \pm 0.21$ \\
10 & $307.77 \pm 2.22$ & $88.63 \pm 1.0$ & $10.34 \pm 1.56$ & $28.68 \pm 2.14$ & $10.13 \pm 1.03$ \\
11 & $307.17 \pm 3.02$ & $90.5 \pm 3.19$ & $9.70 \pm 1.02$ & $15.37 \pm 1.02$ & $26.28 \pm 2.01$ \\
12 & $309.11 \pm 2.01$ & $92.5 \pm 1.23$ & $7.91 \pm 0.77$ & $3.05 \pm 0.21$ & $7.89 \pm 0.97$ \\
13 & $307.08 \pm 2.11$ & $93.2 \pm 0.82$ & $11.97 \pm 1.11$ & $8.08 \pm 0.89$ & $14.93 \pm 1.26$ \\
14 & $298.52 \pm 3.01$ & $89.0 \pm 1.34$ & $6.63 \pm 0.18$ & $4.14 \pm 0.32$ & $8.95 \pm 0.21$ \\
15 & $309.26 \pm 2.26$ & $92.0 \pm 0.32$ & $12.61 \pm 1.05$ & $9.42 \pm 0.32$ & $14.04 \pm 1.21$ \\
16 & $207.49 \pm 2.12$ & $73.9 \pm 0.55$ & $8.00 \pm 0.24$ & $3.42 \pm 0.67$ & $19.91 \pm 1.21$ \\
17 & $260.31 \pm 2.21$ & $82.9 \pm 0.72$ & $3.57 \pm 0.16$ & $2.72 \pm 0.21$ & $2.71 \pm 0.21$ \\
18 & $239.95 \pm 2.31$ & $73.2 \pm 0.18$ & $3.21 \pm 0.23$ & $3.11 \pm 0.43$ & $2.23 \pm 0.13$ \\
19 & $212.73 \pm 2.11$ & $82.6 \pm 2.02$ & $3.11 \pm 0.18$ & $2.35 \pm 0.12$ & $2.62 \pm 0.18$ \\
20 & $169.96 \pm 1.06$ & $70.6 \pm 0.09$ & $2.22 \pm 0.28$ & $2.98 \pm 0.11$ & $1.82 \pm 0.08$ \\
\hline \multicolumn{5}{r}{ TPC $=$ total phenolic content; FA ferulic acid; PC = p-coumaric acid; C = catechin }
\end{tabular}


Table 3: ANOVA for quadratic models of TPC

\begin{tabular}{|c|c|c|c|c|c|}
\hline Source & Sum of squares & $\mathrm{df}$ & Mean Square & F-value & $P$-value \\
\hline Model & 38311.26 & 9 & 4256.807 & 2191.85 & $<0.0001$ \\
\hline$A$ & 237.898 & 1 & 237.898 & 122.4948 & $<0.0001$ \\
\hline$B$ & 1164.521 & 1 & 1164.521 & 599.6174 & $<0.0001$ \\
\hline C & 5863.434 & 1 & 5863.434 & 3019.11 & $<0.0001$ \\
\hline$A B$ & 17.73047 & 1 & 17.73047 & 9.129501 & 0.0129 \\
\hline$A C$ & 114.5327 & 1 & 114.5327 & 58.97344 & $<0.0001$ \\
\hline$B C$ & 4.07525 & 1 & 4.07525 & 2.098366 & 0.1781 \\
\hline$A^{2}$ & 362.2464 & 1 & 362.2464 & 186.5224 & $<0.0001$ \\
\hline$B^{2}$ & 26790.51 & 1 & 26790.51 & 13794.56 & $<0.0001$ \\
\hline$C^{2}$ & 6406.555 & 1 & 6406.555 & 3298.765 & $<0.0001$ \\
\hline Residual & 19.42107 & 10 & 1.942107 & & \\
\hline Lack of Fit & 14.93439 & 5 & 2.986877 & 3.328602 & 0.1065 \\
\hline Total Correlation & 38330.68362 & 19 & & & \\
\hline$R^{2}$ & 0.9995 & & $R_{\text {adj }}^{2}$ & 0.9990 & \\
\hline
\end{tabular}

Table 4: ANOVA for quadratic model of DDPH radical scavenging potential

\begin{tabular}{llllll}
\hline Source & $\begin{array}{l}\text { Sum of } \\
\text { squares }\end{array}$ & $\mathbf{d f}$ & Mean Square & F-value & $\boldsymbol{P}$-value \\
\hline Model & 758.33 & 9 & 84.26 & 2.46 & 0.0883 \\
$A$ & 63.95 & 1 & 63.95 & 1.87 & 0.2015 \\
$B$ & 29.98 & 1 & 29.98 & 0.88 & 0.3713 \\
$C$ & 2.05 & 1 & 2.05 & 0.06 & 0.8114 \\
$A B$ & 0.60 & 1 & 0.60 & 0.02 & 0.8974 \\
$A C$ & 0.00 & 1 & 0.00 & 0.00 & 0.9992 \\
$B C$ & 0.06 & 1 & 0.06 & 0.00 & 0.9662 \\
$A^{2}$ & 2.10 & 1 & 2.10 & 0.06 & 0.8093 \\
$B^{2}$ & 658.44 & 1 & 658.44 & 19.25 & 0.0014 \\
$C^{2}$ & 1.08 & 1 & 1.08 & 0.03 & 0.8627 \\
Residual & 342.12 & 10 & 34.21 & & \\
Lack of Fit & 158.07 & 5 & 31.61 & 0.86 & 0.5643 \\
Total Correlation & 1100.45 & 19 & & & \\
$R^{2}$ & 0.6891 & & $R_{\text {adj }}^{2}$ & 0.4093 & \\
\hline
\end{tabular}

$\mathrm{Y}=308.10+4.17 \times \mathrm{A}-9.23 \times \mathrm{B}+20.72 \times \mathrm{V}+1.49 \times \mathrm{AB}+$ $3.78 \times A C-0.71 \times B C-5.01 \times A 2-43.12 \times B^{2}-21.08 \times C^{2}$

(B variables with negative coefficients depict decreased response, while increase in response was due to positive coefficients of the variables $A$ and $\mathrm{C}$ ).

Table 4 depicts results of fitting models for DPPH radical scavenging activity. F-test and $p$ value were used to assess the model significance. The $p$ value was 0.0883 , which suggests adequacy of the model for use as a predictor within the range of experimental variables.

Table 5 shows the design matrix and results of ANOVA, fitness and adequacy of the models for ferulic acid content. The determination coefficient $\left(R^{2}\right)$ obtained from variance of quadratic regression model was 0.6952 . This demonstrates the inadequacy of the model for explaining total variance. In addition, the adjusted $R^{2}$ value was 0.4209 which also showed that the model lacked significance. The model was also inadequate for making predictions over the range of variables 
used in the experiment. The values of the regression coefficients (Table 5 ) indicate that $C^{2}$ was significantly different $(p<0.05)$. However, there were no significant differences between $A B, A C$ and $B C$.

Table 6 shows that the multiple correlation coefficient $(r)$ and determination coefficient $\left(R^{2}\right)$ were not satisfactory to describe $p$-coumaric acid. The value of $R^{2}$ from the quadratic regression model was 0.4397 , suggesting that the model cannot explain the total variance.

Table 7, the quadratic models lacked significance and fit $(p>0.05)$ with respect to catechin. In addition, the regression model produced $R^{2}$ value of 0.5489 . These results indicate that the model cannot explain total variance.
Figure 1 shows contour plot response surfaces of TPC. A significant influence was produced on maximization of TPC extract by the two-factor interaction between temperature and solvent concentration $(A B, p<0.05)$. From the results, it is clear that $50-70 \% \quad(\mathrm{v} / \mathrm{v})$ ethanol and temperatures above $45{ }^{\circ} \mathrm{C}$ yielded high extracts of TPC (Figures $1 \mathrm{~A}$ and $1 \mathrm{~B}$ ).

Similarly, the interaction between solvent concentration and extraction time (AC) had significant effect $(p<0.05)$ on TPC extraction. Moreover, ethanol concentrations within the range 50 - $70 \%(\mathrm{v} / \mathrm{v})$, and extraction times above $2.5 \mathrm{~h}$ resulted in higher TPC yields (Figures 1C and 1D). However, no significant effect was produced on the extraction of TPC by the interaction between extraction temperature and extraction time (BC, $p>0.05)$.

Table 5: ANOVA for ferulic acid quadratic models

\begin{tabular}{llllll}
\hline Source & Sum of squares & Df & Mean square & F-value & $P$-value \\
\hline Model & 809.79 & 9.00 & 89.98 & 2.53 & 0.0818 \\
$A$ & 91.74 & 1.00 & 91.74 & 2.58 & 0.1390 \\
$B$ & 101.80 & 1.00 & 101.80 & 2.87 & 0.1212 \\
$C$ & 88.21 & 1.00 & 88.21 & 2.48 & 0.1460 \\
$A B$ & 1.19 & 1.00 & 1.19 & 0.03 & 0.8584 \\
$A C$ & 39.84 & 1.00 & 39.84 & 1.12 & 0.3143 \\
$B C$ & 25.48 & 1.00 & 25.48 & 0.72 & 0.4167 \\
$A^{2}$ & 0.00 & 1.00 & 0.00 & 0.00 & 0.9961 \\
$B^{2}$ & 171.14 & 1.00 & 171.14 & 4.82 & 0.0528 \\
$C^{2}$ & 245.12 & 1.00 & 245.12 & 6.90 & 0.0253 \\
Residual & 355.00 & 10.00 & 35.50 & & \\
Lack of Fit & 332.54 & 5.00 & 66.51 & 14.80 & 0.0051 \\
Total & 1164.79 & 19.00 & & & \\
Correlation & 0.6952 & & $R_{\text {adj }}^{2}$ & 0.4209 & \\
$R^{亡}$ & & & &
\end{tabular}

Table 6: ANOVA for p-coumaric acid quadratic models

\begin{tabular}{llrlll}
\hline Source & Sum of squares & Df & Mean square & F-value & $P$-value \\
\hline Model & 1323.87 & 3.00 & 441.29 & 4.19 & 0.0229 \\
$A$ & 162.37 & 1.00 & 162.37 & 1.54 & 0.2325 \\
$B$ & 1001.72 & 1.00 & 1001.72 & 9.50 & 0.0071 \\
$C$ & 159.78 & 1.00 & 159.78 & 1.52 & 0.2361 \\
Residual & 1687.02 & 16.00 & 105.44 & & \\
Lack of Fit & 1224.92 & 11.00 & 111.36 & 1.20 & 0.4457 \\
Total & 3010.89 & 19.00 & & & \\
Correlation & 0.4397 & & $R^{2}$ adj & 0.3346 & \\
$R^{2}$ & & & & &
\end{tabular}


Table 7: ANOVA for catechin quadratic models

\begin{tabular}{llllll}
\hline Source & Sum of squares & Df & Mean square & F-value & $P$-value \\
\hline Model & 409.06 & 9.00 & 45.45 & 1.35 & 0.3214 \\
$A$ & 1.99 & 1.00 & 1.99 & 0.06 & 0.8127 \\
$B$ & 94.74 & 1.00 & 94.74 & 2.82 & 0.1242 \\
$C$ & 39.23 & 1.00 & 39.23 & 1.17 & 0.3054 \\
$A B$ & 81.78 & 1.00 & 81.78 & 2.43 & 0.1499 \\
$A C$ & 44.24 & 1.00 & 44.24 & 1.32 & 0.2780 \\
$B C$ & 4.79 & 1.00 & 4.79 & 0.14 & 0.7137 \\
$A^{2}$ & 44.55 & 1.00 & 44.55 & 1.32 & 0.2765 \\
$B^{2}$ & 102.38 & 1.00 & 102.38 & 3.04 & 0.1116 \\
$C^{2}$ & 17.81 & 1.00 & 17.81 & 0.53 & 0.4834 \\
Residual & 336.24 & 10.00 & 33.62 & & \\
Lack of Fit & 133.45 & 5.00 & 26.69 & 0.66 & 0.6713 \\
Total Correlation & 745.30 & 19.00 & & & \\
$R^{2}$ & 0.5489 & & $R^{2}{ }_{\text {adj }}$ & 0.1428 & \\
\hline
\end{tabular}
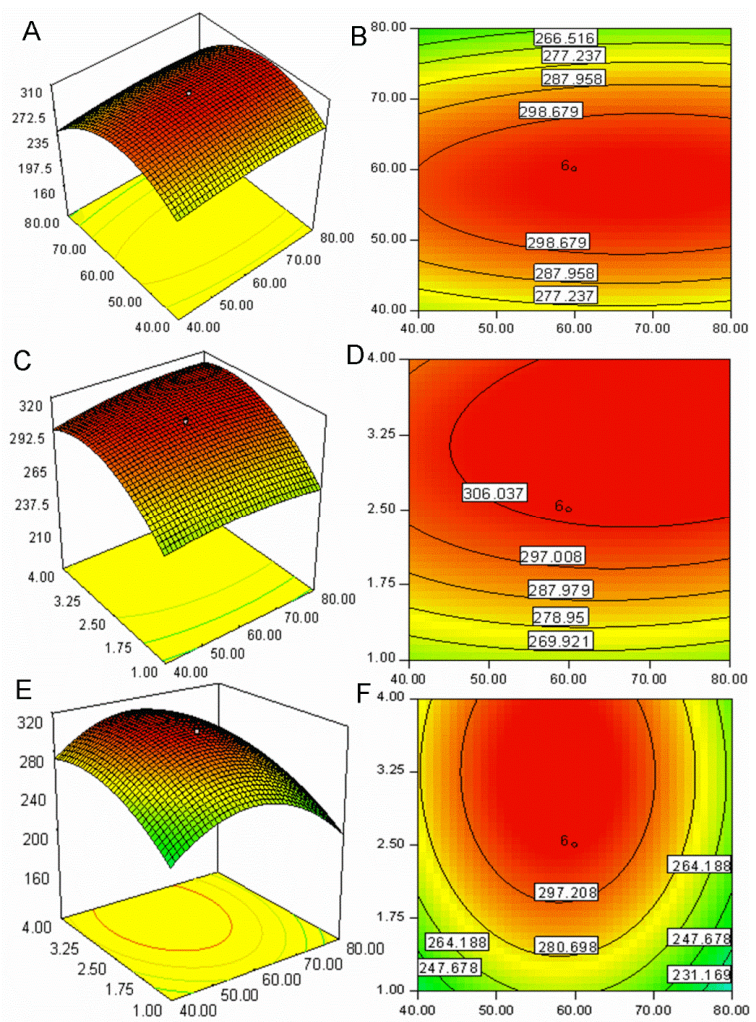

Figure 1: RSM plots and contour plots depicting effects of interaction between temperature, extraction time and solvent on TPC level. A, B: ethanol interaction with temperature; C, D: solvent interaction with solvent and extraction time; E, F: temperature interaction with extraction time

\section{Correlations}

Results on Table 8 indicate matrices of correlation coefficients amongst the four parameters determined. TPC was strongly associated with DPPH radical scavenging potential $(r=0.67)$, while between $p$-coumaric acid was strongly associated with ferulic acid $(r=$ $0.54)(p<0.05)$.

Table 8: Pearson's correlation coefficients between polyphenolics and antioxidant activity

\begin{tabular}{|c|c|c|c|c|c|}
\hline Variable & $\begin{array}{l}0 \\
k\end{array}$ & $\frac{\frac{T}{a}}{\frac{a}{a}}$ & 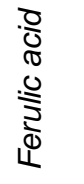 & 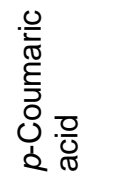 & $\begin{array}{l}\stackrel{5}{\mathbb{S}} \\
\frac{\mathbb{J}}{\mathbb{J}}\end{array}$ \\
\hline$\overline{\text { TPC }}$ & 1.00 & & & & \\
\hline DPPH & $0.67^{\circ}$ & 1.00 & & & \\
\hline Ferulic acid & 0.28 & 0.44 & 1.00 & & \\
\hline $\begin{array}{l}p \text {-Coumaric acid } \\
\text { Catechin }\end{array}$ & $\begin{array}{l}0.03 \\
0.32\end{array}$ & $\begin{array}{l}0.28 \\
0.26\end{array}$ & $\begin{array}{l}0.47 \\
0.19\end{array}$ & $\begin{array}{l}1.00 \\
0.15\end{array}$ & 1.00 \\
\hline
\end{tabular}

${ }^{*}$ Correlation is significant at the $p<0.05$ level

\section{DISCUSSION}

Sorghum $\mathrm{M}$. is one of the most important cereal crops, commonly grown around the globe. It is consumed by humans in the form of alcohol (commercial product of Sorghum) and also used as animal feed. Natural antioxidants in Sorghum i.e. polyphenolics and phytosterols play significant roles against oxidative stress, and provide protection against degenerative diseases, cancers, ageing, cardiovascular disorders and diabetes. It is well established that various factors like type of solvent and extraction duration affect the stability and yield of phytochemicals. 
Thus, in this study, RSM was used to optimize variables that appreciably affect the extraction of phytochemicals from Sorghum M. Total phenolic content and DPPH radical scavenging activity were $309.26 \pm 2.26 \mathrm{mg} \mathrm{GAE} / 100 \mathrm{~g} \mathrm{DW}$ and 93.20 \pm 0.82 , respectively, which are lower than values reported in previous studies [11]. This disparity may be attributed to differences in methods used for extraction. In RSM, the variables were catechin, TPC, ferulic acid, DPPH scavenging and $p$ - coumeric acid. It has been demonstrated that values of $R^{2}$ close to unity indicate close fit between experimental error [12].

Overall, Sorghum $M$ sample extracted for 3 hours at $60{ }^{\circ} \mathrm{C}$ using $60 \%$ ethanol resulted in maximum TPC. It was noted that long extraction time favored the extraction of polyphenols. This is so because, long time exposure of sample allows solvent molecules to penetrate in the plant tissues/cells to dissolve out more of the phytochemical compounds [13].

In the present study, extraction time also exhibited significant effect on the extraction of TPCs and phenolic acids. The maximum extraction of phenolic compounds at high temperature might be due to tissue softening, breakage of bonds linking polyphenolics and protein or polysaccharides, increases in the solubility of the phenolic compounds, and decreases in surface tension and viscosity of the solvent. These factors enhance diffusion and so result in high extraction of TPC [14]. However, this effect is limited because many phenolic compounds such as flavonols, flavonoids and flavonones are degraded at high temperatures, thereby resulting in lower yields. Temperature and concentration interacted in a manner that significantly influenced the yield of TPC, and DPPH scavenging potential showed positive correlation with TPC. The ability of the RSM model to predict TPC yield was tested at the optimal concentration of ethanol i.e. $60 \%$ ethanol, optimal temperature for extraction i.e. 60 ${ }^{\circ} \mathrm{C}$, and extraction duration of $3 \mathrm{~h}$. Under these conditions, the yield of TPC was $315.87 \mathrm{mg}$ $\mathrm{GAE} / 100 \mathrm{gDW}$, which indicate that the RSM model has very good and accurate predictive capacity for TPC yield.

\section{CONCLUSION}

The results of this study show that extraction time of $3 \mathrm{~h}$, extraction temperature of $60^{\circ} \mathrm{C}$ and use of $60 \%$ ethanol were the best conditions for maximum extraction of TPCs from Sorghum $m$. These findings confirm that RSM is an important strategy for maximizing the extraction of natural antioxidants. Consequently, this approach may also helpful for maximum extraction of useful phytochemicals on commercial basis.

\section{DECLARATIONS}

\section{Acknowledgement}

This work was financially supported by China Postdoctoral Science Foundation Funded Project (no. 2016M602605) andthe Project of Natural Science Foundation of Jiangsu Province (no. BK20130410).

\section{Conflict of interest}

No conflict of interest is associated with this study.

\section{Contribution of authors}

The authors declare that this work was done by the authors named in this article and all liabilities pertaining to claims relating to the content of this article will be borne by them.

\section{REFERENCES}

1. Awika JM, Dykes L, Gu LW, Rooney LW, Prior R. Effect of processing on molecular weight distribution and antioxidant properties of sorghum proanthocyanidins. Abstr Pap Am Chem Soc 2004; 228: U248-U248.

2. Awika JM, Rooney LW. Sorghum phytochemicals and their potential impact on human health. Phytochemistry 2004; 65(9): 1199-1221.

3. Choi $Y$, Jeong HS, Lee J. Antioxidant activity of methanolic extracts from some grains consumed in Korea. Food Chem 2007; 103(1): 130-138.

4. Liu B, Ma Y, Liu Y, Yang Z, Zhang L. Ultrasonic-Assisted Extraction and Antioxidant Activity of Flavonoids from Adinandra nitida Leaves. Trop J Pharm Res 2013; 12(6): 1045-1051.

5. Yuan $C$, Liu B, Chen $Y$, Chen $Y$. Optimization of Preparation of Jujube Juice by Response Surface Methodology. In Future Material Research and Industry Application 2012; 455-456: 981-984.

6. Yasini $P$, Shemirani F, Khani R. Combination of In Situ Surfactant-based Solid Phase Extraction and Central Composite Design for Preconcentration and Determination of Manganese in Food and Water Samples. Food Anal Method 2012; 5(6): 1303-1310.

7. Liu MX, Wang YW, Han JG, Mao PS. Phenolic compounds from Chinese sudangrass, sorghum, sorghum-sudangrass hybrid, and their antioxidant properties. Crop Sci 2011; 51(1): 247-258.

8. Chen Y, Chen G, Fu X, Liu RH. Phytochemical profiles and antioxidant activity of different varieties of Adinandra tea (Adinandra Jack). J Agric Food Chem 2015; 63(1):169-176. 
9. Guo XD, Ma YJ, Parry J, Gao JM, Yu LL, Wang M. Phenolics Content and Antioxidant Activity of Tartary Buckwheat from Different Locations. Molecules 2011; 16(12): 9850-9867.

10. Chen Y, Zhang R, Liu C, Zheng X, Liu B. Enhancing antioxidant activity and antiproliferation of wheat bran through steam flash explosion. J Food Sci Tech 2016; 53(7): 3028-3034.

11. Dykes L, Rooney LW, Waniska RD, Rooney WL. Phenolic compounds and antioxidant activity of sorghum grains of varying genotypes. J Agric Food Chem 2005; 53(17): 6813-6818.
12. Lee WC, Yusof S, Hamid NSA, Baharin BS. Optimizing conditions for enzymatic clarification of banana juice using response surface methodology (RSM). J Food Eng 2006; 73(1): 55-63.

13. Gan $C Y$, Latiff $A A$. Optimisation of the solvent extraction of bioactive compounds from Parkia speciosa pod using response surface methodology. Food Chem 2011; 124(3): 1277-1283.

14. Kusic H, Koprivanac N, Papic S, Bozic AL. Influence of substituent type and position on photooxidation of phenolic compounds: Response surface methodology approach. J Photoch Photobio A Chem 2012; 242(31): 1-12. 